\title{
Assessment of the usefulness of imaging studies and biomarkers in the activity of Crohn's disease
}

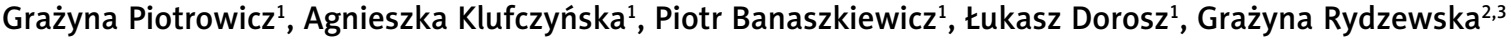 \\ ${ }^{1}$ Department of Gastroenterology, Self-Dependent Health Care Unit of Ministry of Interior, Gdansk, Poland \\ ${ }^{2}$ Department of Gastroenterology with Inflammatory Bowel Disease Subdivision, Central Clinical Hospital of the Ministry \\ of the Interior and Administration, Warsaw, Poland \\ ${ }^{3}$ Faculty of Medicine and Health Sciences, Jan Kochanowski University, Kielce, Poland
}

Gastroenterology Rev 2021; 16 (1): 15-22

DOI: https://doi.org/10.5114/pg.2020.93539

Key words: Crohn's Disease Activity Index, simple endoscopic score index, faecal calprotectin, magnetic resonance enterography.

Address for correspondence: Grażyna Piotrowicz MD, PhD, Department of Gastroenterology, Self-Dependent Health Care Unit of Ministry of Interior, 4/6 Kartuska St, 80-104 Gdansk, Poland, phone: +48 602784 507, e-mail: piotrowicz.grazyna@interia.eu

\begin{abstract}
Aim: The aim of the study was to determine the suitability of available diagnostic methods, by means of comparison, for predicting disease activity, based on cost efficiency and sensitivity criteria.

Material and methods: In this study, we conducted analyses of 37 patients with Crohn's disease (CD). CD was graded as "active" or "inactive" by adopting certain cut-off values for every marker. The main assumption was that methods used to grade CD severity do not give false positive results. The authors decided to measure the agreement between the methods by applying Cohen's $\kappa$ coefficient.

Results: Endoscopy shows the highest sensitivity, negative predictive value, and accuracy in detecting CD. In the case of both intestines, the sensitivity of endoscopy reached $93.9 \%$ and the accuracy $94.6 \%$, while the sensitivity and accuracy of enterography and calprotectin were $51.5 \%$ vs. $71,9 \%$ and $56.8 \%$ vs. $72.2 \%$, respectively. For the large intestine, the sensitivity and accuracy of endoscopy reached $100 \%$. For the small intestine, endoscopy had $55 \%$ sensitivity and $75 \%$ accuracy, while enterography showed only $66.7 \%$ and $81.1 \%$, respectively. The best agreement $(77.1 \%, p=0.005)$ was seen between endoscopy and calprotectin for full intestines. However, the value of Cohen's $\kappa$ suggests that this agreement is moderate. The optimal cut-off value for calprotectin was $43 \mu \mathrm{g} / \mathrm{g}$, and the ROC curve $(A U C=0.871)$ was large enough to conclude that calprotectin is a statistically significant $(p<0.001)$ indicator of CD activity.
\end{abstract}

Conclusions: Statistically significant compliance was shown only between colonoscopy and faecal calprotectin.

\section{Introduction}

Inflammatory bowel diseases like Crohn's disease (CD) or ulcerative colitis represent a group of chronic conditions characterised by periods of flare-ups and remissions.

Currently, different methods are used to assess the activity of the disease, including the following: Crohn's Disease Activity Index (CDAI), inflammatory biomarkers, and medical imaging, which shows the severity of inflammatory changes.

Crohn's Disease Activity Index is considered the gold standard for assessing the clinical condition of patients. According to ECCO guidelines, a CDAI score
$<150.0$ points indicates a remission, whereas a CDAI score $>220.0$ points indicates disease exacerbation [1]. Biomarkers used in laboratory tests include the following: C-reactive protein (CRP), haemoglobin, leukocytes, thrombocytes, serum iron, ferritin, ceruloplasmin, $\alpha 1$-antitripsin, plasminogen, fibrinogen, interleukin 6, salicylic acid, and amyloid A [2]. Faecal biomarkers include: faecal calprotectin (FC), faecal lactoferrin (FL), elastase, myeloperoxidase, metalloproteinase 9 , and neoprotein [3].

CRP, a protein produced by hepatocytes [4], is not characteristic solely of inflammatory bowel disease (IBD). The CRP level is elevated in other inflammatory diseases as well $[4,5]$. 
There is a correlation between elevated CRP levels and the clinical activity of CD [6-8]; however, in 20.0$25.0 \%$ of patients with severe $C D$, there is no increase in the CRP level due to a single-nucleotide polymorphism in the CRP gene [9].

Faecal calprotectin is an inflammatory protein found in the cytosol of human neutrophils, macrophages, and monocytes [10-12]. When inflammation is present, the FC level is in direct proportion to the migration of neutrophils to the digestive tract. This is the reason for increased levels of FC in the case of inflammatory diseases of the digestive tract in general. FC has already been adapted in clinical practice in Western Europe as a surrogate marker for intestinal inflammation. It correlates strongly with endoscopic scores of activity [5, 13-18], and from an economic point of view it is cheaper, faster, and more patient friendly than the standard endoscopic procedures [15].

Magnetic resonance enterography (MRE), an examination used for visualising small intestine damage, is an important complementary test to colonoscopy. Along with biochemical endoscopic assessments, MRE is used to diagnose and assess the activity of inflammatory bowel disease (IBD); nevertheless, ileocolonoscopy with biopsy remains the first-line diagnostic tool [16-18]. MRE and computed tomography enterography (CTE) are imaging techniques used to investigate intramural changes and complications of CD [19-21].

MRE is recommended by ECCO, not only as a diagnostic tool, but also as a monitoring tool in patients with CD $[17,18]$. A comparison study conducted to evaluate the diagnostic value of MRE and ileocolonoscopy in monitoring the response to treatment in patients with $C D$ showed that both methods have a similar degree of reliability when it comes to assessing the healing of changes (90.0\% vs. 83.0\%) [22].

Colonoscopy is a recommended method for assessing disease activity in the large intestine and the distal segment of the ileum. Currently, two methods are applied to assess the inflammation: SES-CD (simple endoscopic score index) and CDEIS (Crohn's disease index of severity) [23]. Both methods involve the use of video colonoscopy. The study described in this article was performed to assess and compare methods used for the assessment of inflammation activity in CD, such as: blood and faecal biomarkers, imaging techniques, and clinical assessment based on CDAI.

\section{Aim}

The aim of the study was to determine which method is the most accurate and could therefore be used to optimise the monitoring of patients, as well as to modify the currently used methods of treatment.

\section{Material and methods \\ Study design}

The study enrolled 37 patients with $C D$, hospitalised in the Department of Gastroenterology of the Self-Dependent Health Care Unit of Ministry of Interior in Gdansk in 2015-2017 to assess CD activity based on CDAl, blood biomarkers (haemoglobin, thrombocytes, iron, C-reactive protein (CRP)), faecal biomarker (calprotectin), and imaging techniques (ileocolonoscopy and magnetic resonance enterography).

Tests were conducted at a 1-week interval between imaging examinations, and other laboratory analyses were performed at a single stage, $24 \mathrm{~h}$ before colonoscopy.

The CDAl calculator takes into consideration: sex, weight, height, age, haematocrit, presence of abdominal masses, extra-intestinal complications, anti-diarrhoea drug use, number of soft/liquid stools, severity of abdominal pain, and patient's general well-being.

$C D$ may be active or inactive. The cut-off values were set at CDAl score $\leq 150.0$ for the inactive disease and at CDAl score $>150.0$ for the active disease.

An immunoturbidimetric method was used to assay serum CRP, which is a test for quantitative determination with high sensitivity, using antibodies coated on latex, against this human acute phase protein [24]. The cut-off value of $5.0 \mathrm{mg} / \mathrm{dl}$ was set to differentiate between the active disease (above the cut-off level) and inactive disease (below the cut-off level).

Faecal calprotectin was measured using the Quantum Blue calprotectin test for the quantitative measurement of calprotectin level in faecal samples.

Stool samples were stored in a refrigerator at 2.0$8.0^{\circ} \mathrm{C}$ and examined within $24 \mathrm{~h}$, similarly to specimen tubes. Stool samples and specimen tubes were stored at room temperature $\left(24.0 \pm 4.0^{\circ} \mathrm{C}\right)$ for $20.0 \mathrm{~min}$ before the procedure. Next, each stool sample was disrupted and dissolved in an extraction buffer. An automatic pipette was used to collect a faecal specimen, which was then inserted into a separate specimen tube and dissolved in the "chase buffer" in a $1: 15$ ratio $(20.0 \mu$ l of the specimen $+280.0 \mu$ lof the buffer). The reader was calibrated to an extended range (30.0-1800.0 $\mu \mathrm{g} / \mathrm{g})$, and a faecal extract of $60.0 \mu \mathrm{l}$ was loaded onto the loading port of the test cassette. After 12.0 min of incubation, the extract was put on a tray. The test cassette was automatically read, and the result was displayed on a screen. The cut-off value was set at $100.0 \mu \mathrm{g} / \mathrm{g}$ for disease activity.

In ileocolonoscopy, a SES-CD score was used to assess the disease activity. Five bowel segments were examined, and the following criteria were used to assess the severity of the disease. 
Adding the scores from all five segments assessed the disease activity. The final score was interpreted in the following manner: $\leq 2.0$ : inactive $C D ; 3.0-6.0$ : mild CD; 7.0-15.0: moderate CD; > 16.0: severe CD.

For the purposes of this study, a score $\leq 2.0$ points was considered indicative of an inactive inflammation process. Scores above 2.0 points, on the other hand, were indicative of an active inflammation process.

In MRE, the disease activity was assessed as active or inactive (by assessing the location of changes and the severity of the inflammation process) in the small and large intestine, based on the following examination protocol. Before the examination, a patient is asked to drink approx. 1.5 I of $3.0 \%$ mannitol solution over $60 \mathrm{~min}$. During the examination, a contrast agent is administered (ProHance or Gadovist), and the following sequences are analysed according to the protocol:

1. T2 haste cor slice $3.5 \mathrm{~mm}$ gap $0 \mathrm{~mm}$, TR $1200 \mathrm{~ms}$ TE $100 \mathrm{~ms}$, matrix $288 \times 384$.

2. T2 haste stir cor slice $4 \mathrm{~mm}$ gap $0 \mathrm{~mm}$, TR $1200 \mathrm{~ms}$ TE 100 ms, TI 180 ms, matrix $288 \times 384$.

3. T2 trufi cor slice $4 \mathrm{~mm}$ gap $0 \mathrm{~mm}$, TR $3.51 \mathrm{~ms}$ TE $1.45 \mathrm{~ms}$, matrix $167 \times 256$.

4. DWI cor slice $5 \mathrm{~mm}$ gap $0 \mathrm{~mm}$, TR $6400 \mathrm{~ms}$ TE $65 \mathrm{~ms}$, matrix $160 \times 160, b=0.50,500,800$.

5. T2 haste tra slice $4 \mathrm{~mm}$ gap $0 \mathrm{~mm}$, TR $1200 \mathrm{~ms}$ TE $102 \mathrm{~ms}$, matrix $260 \times 320$.

6. T1 flash tra slice $4 \mathrm{~mm}$ gap $0.8 \mathrm{~mm}$, TR $189 \mathrm{~mm}$ TE $4.93 \mathrm{~ms}$, matrix $203 \times 320$.

7. T1 vibe fs cor dynamika CM slice $3 \mathrm{~mm}$ gap $0.6 \mathrm{~mm}$, TR 4.36 ms TE $1.92 \mathrm{~ms}$, matrix $183 \times 288$, dynamic $-8$.

8. T1 flash fs tra slice $4 \mathrm{~mm}$ gap $0.8 \mathrm{~mm}$, TR $145 \mathrm{~ms}$ TE $2.38 \mathrm{~ms}$, matrix $167 \times 256$.

\section{Statistical analysis}

All data were compared by means of statistical analysis to determine the correlation between them and, at the same time, to identify the usefulness of particular markers of disease activity with reference to their sensitivity, specificity, and reliability, which has an impact on retesting and economic aspects of different tests.

The main assumption of the analysis was that methods used to detect CD activity (CDAl, endoscopy, enterography, and calprotectin) do not give false positive results. Moreover, none of these methods was considered a reference method. The true positive conditions were defined when either of the methods yielded a positive result. In other words, true negative conditions were specified when an investigation by all three methods brought a negative result. This implied that specificity and PPV (positive predictive value) were equal to $100.0 \%$. Therefore, the comparison of methods presented in the article was based on sensitivity, negative predictive value (NPV), and accuracy. The authors also decided to measure the agreement between all methods based on the Cohen's $\kappa$ coefficient and compare them to the CDAl-based method.

Additionally, an optimal cut-off value was set for calprotectin, based on the ROC curve, with the use of two techniques: the tangent method and Youden index. Finally, all comparative analyses were performed separately for the small and large intestine, when possible.

The level of significance was set at $\alpha=0.05$, and all statistical analyses were performed using Statistica version 12.5 .

The analysis was based on the following assumptions:

- There is no gold standard when it comes to detecting disease activity in the small and large intestine.

- Methods based on endoscopy and enterography have a positive predictive value (PPV $=100.0 \%)$, which means that if a patient is diagnosed with an active disease, the diagnosis is $100.0 \%$ certain - there are no false positive results (specificity $=100.0 \%$ ).

A variable was defined as "reality", which showed whether the disease was active, i.e. whether any of the two imaging techniques (endoscopy or enterography) revealed the activity of the disease.

It was assumed that:

- CDAl score $>150.0$ points indicates disease activity, - SES-CD score $>2.0$ points indicates disease activity, - CRP level > $5.0 \mathrm{mg} / \mathrm{dl}$ indicates disease activity,

- Calprotectin level > 100.0 Mg/g indicates disease activity.

\section{Results}

\section{Approach no. 1}

When the disease activity is assessed without dividing the intestine into segments - i.e. in the small and large intestine as a whole - it means that the disease is considered active if it occurs in any of the two bowel segments (Tables I-V).

\section{Approach no. 2}

If we treat the assessment of disease activity separately, i.e. we analyse these exponents separately for changes in the small intestine and separately for changes in the large intestine, the statistical evaluation of the diagnostic methods used will be as follows:

\section{Small intestine}

Tables VI-VIII. 


\section{Large intestine}

Tables IX-XI.

\section{Agreement of methods}

The agreement of methods was assessed using an unadjusted coefficient of agreement and the Cohen's $\kappa$ coefficient (Table XII).

Table I. Endoscopy

\begin{tabular}{|c|c|c|}
\hline \multirow{2}{*}{$\begin{array}{l}\text { Observed frequency - } \\
\text { ileocolonoscopy }\end{array}$} & \multicolumn{2}{|c|}{ Reality } \\
\hline & Active & Inactive \\
\hline Active & 31 & 0 \\
\hline Inactive & 2 & 4 \\
\hline Total & 33 & 4 \\
\hline
\end{tabular}

Table II. Magnetic resonance imaging

\begin{tabular}{lcc} 
Observed frequency & \multicolumn{2}{c}{ Reality } \\
\cline { 2 - 3 } MR enterography & Active & Inactive \\
\hline Active & 17 & 0 \\
\hline Inactive & 16 & 4 \\
\hline Total & 33 & 4
\end{tabular}

Table III. Calprotectin

\begin{tabular}{lcc} 
Observed frequency & \multicolumn{2}{c}{ Reality } \\
\cline { 2 - 3 } faecal calprotectin & Active & Inactive \\
\hline Active & 24 & 1 \\
\hline Inactive & 9 & 3 \\
\hline Total & 33 & 4
\end{tabular}

Table IV. C-reactive protein (CRP)

\begin{tabular}{lcc} 
Observed frequency & \multicolumn{2}{c}{ Reality (for both intestines) } \\
\cline { 2 - 3 } & Active & Inactive \\
\hline Active & 20 & 0 \\
\hline Inactive & 14 & 3 \\
\hline Total & 34 & 3
\end{tabular}

Table V. CDAl

\begin{tabular}{lcc} 
Observed frequency & \multicolumn{2}{c}{ Reality } \\
\cline { 2 - 3 }- CDAI & Active & Inactive \\
\hline Active & 25 & 3 \\
\hline Inactive & 8 & 1 \\
\hline Total & 33 & 4
\end{tabular}

Table VI. Endoscopy

\begin{tabular}{lcc} 
Observed frequency & \multicolumn{2}{c}{ Reality } \\
\cline { 2 - 3 } $\begin{array}{l}\text { endoscopy (small } \\
\text { intestine) }\end{array}$ & Active & Inactive \\
\hline Active & 12 & 0 \\
\hline Inactive & 9 & 16 \\
\hline Total & 21 & 16
\end{tabular}

Table VII. Magnetic resonance imaging

\begin{tabular}{lcc} 
Observed frequency & \multicolumn{2}{c}{ Reality } \\
\cline { 2 - 3 } $\begin{array}{l}\text { MR enterography } \\
\text { (small intestine) }\end{array}$ & Active & Inactive \\
\hline Active & 14 & 0 \\
\hline Inactive & 7 & 16 \\
\hline Total & 21 & 16
\end{tabular}

Table VIII. C-reactive protein (CRP)

\begin{tabular}{lcc} 
Observed frequency - & \multicolumn{2}{c}{ Reality } \\
\cline { 2 - 3 } CRP (small intestine) & Active & Inactive \\
\hline Active & 14 & 5 \\
\hline Inactive & 7 & 11 \\
\hline Total & 21 & 16
\end{tabular}

Table IX. Endoscopy

\begin{tabular}{lcc} 
Observed frequency & \multicolumn{2}{c}{ Reality } \\
\cline { 2 - 3 } $\begin{array}{l}\text { endoscopy (large } \\
\text { intestine) }\end{array}$ & Active & Inactive \\
\hline Active & 27 & 0 \\
\hline Inactive & 1 & 9 \\
\hline Total & 28 & 9
\end{tabular}

Table X. Magnetic resonance imaging

\begin{tabular}{lcc} 
Observed frequency & \multicolumn{2}{c}{ Reality } \\
\cline { 2 - 3 } $\begin{array}{l}\text { MR enterography } \\
\text { (large intestine) }\end{array}$ & Active & Inactive \\
\hline Active & 9 & 0 \\
\hline Inactive & 19 & 9 \\
\hline Total & 28 & 9
\end{tabular}

Table XI. C-reactive protein (CRP)

\begin{tabular}{ccc} 
Observed frequency - & \multicolumn{3}{c}{ Reality } \\
\cline { 2 - 3 } CRP (large intestine) & Active & Inactive \\
\hline Active & 18 & 1 \\
\hline Inactive & 10 & 8 \\
\hline Total & 28 & 9
\end{tabular}


A statistically significant agreement of methods was identified in the case of endoscopy and calprotectin, as well as CRP values and CDAI values.

There was a correlation between CRP and calprotectin, CRP and enterography of the small intestine, and CRP and colonoscopy of the large intestine.

\section{Calprotectin cut-off values}

Table XIII.

\section{ROC curve for calprotectin}

Calprotectin shows a high degree of effectiveness in the detection of $C D$ activity in the large intestine and the bowel in general. However, the level of this biomarker should not be used for assessment of the disease activity solely within the small intestine.

According to the Youden Index, the cut-off value of $100.0 \mu \mathrm{g} / \mathrm{g}$ (sensitivity $=88.9 \%$, specificity $=87.5 \%$ ) and $43.0 \mu \mathrm{g} / \mathrm{g}$ (sensitivity $=93.8 \%$, specificity $=75.0 \%$ ) should be used for the large intestine and a full-scope detection, respectively (Figure 1).

\section{Discussion}

Recently, clinical management of patients with IBD has evolved, with the main aim now being not only clinical remission, but also mucosal healing.

Table XII. Agreement of methods

\begin{tabular}{|c|c|c|c|c|}
\hline \multicolumn{2}{|l|}{ Compared methods } & \multirow{2}{*}{$\frac{\text { Coefficient of agreement (\%) }}{50.0}$} & \multirow{2}{*}{$\frac{\text { Cohen's } \kappa}{0.069}$} & \multirow{2}{*}{$\frac{P \text {-value }}{0.549}$} \\
\hline Ileocolonoscopy & MR enterography & & & \\
\hline & Faecal calprotectin & 77.1 & 0.424 & 0.005 \\
\hline MR Enterography & Faecal calprotectin & 54.3 & 0.094 & 0.555 \\
\hline \multirow[t]{3}{*}{ CDAI } & Ileocolonoscopy & 52.6 & -0.305 & 0.179 \\
\hline & MR enterography & 57.9 & 0.283 & 0.078 \\
\hline & Faecal calprotectin & 52.9 & 0.029 & 0.893 \\
\hline $\begin{array}{l}\text { Endoscopy } \\
\text { (small intestine) }\end{array}$ & $\begin{array}{l}\text { MR enterography } \\
\text { (small intestine) }\end{array}$ & 57.9 & 0.038 & 0.865 \\
\hline $\begin{array}{l}\text { Endoscopy } \\
\text { (large intestine) }\end{array}$ & $\begin{array}{l}\text { MR enterography } \\
\text { (large intestine) }\end{array}$ & 47.4 & 0.159 & 0.2 \\
\hline \multirow[t]{8}{*}{ CRP } & Ileocolonoscopy & 67.6 & 0.339 & 0.006 \\
\hline & MR enterography & 67.60 & 0.353 & 0.031 \\
\hline & Faecal calprotectin & 72.2 & 0.423 & 0.009 \\
\hline & CDAI & 76.3 & 0.513 & $<0.001$ \\
\hline & $\begin{array}{c}\text { Endoscopy } \\
\text { (small intestine) }\end{array}$ & 62.2 & 0.251 & 0.091 \\
\hline & $\begin{array}{l}\text { MR enterography } \\
\text { (small intestine) }\end{array}$ & 70.3 & 0.409 & 0.010 \\
\hline & $\begin{array}{c}\text { Endoscopy } \\
\text { (large intestine) }\end{array}$ & 67.6 & 0.343 & 0.020 \\
\hline & $\begin{array}{l}\text { MR enterography } \\
\text { (large intestine) }\end{array}$ & 56.8 & 0.147 & 0.291 \\
\hline
\end{tabular}

Table XIII. Calprotectin values

\begin{tabular}{lcccc} 
Scope & \multicolumn{2}{c}{ Cut-off values according to } & AUC & P-value \\
\cline { 2 - 4 } & Tangent method & Youden Index & 0.871 & 0.439 \\
\hline Small and large intestine & 43 & 43 & 61 & 0.001 \\
\hline Small intestine & 61 & 100 & 0.944
\end{tabular}




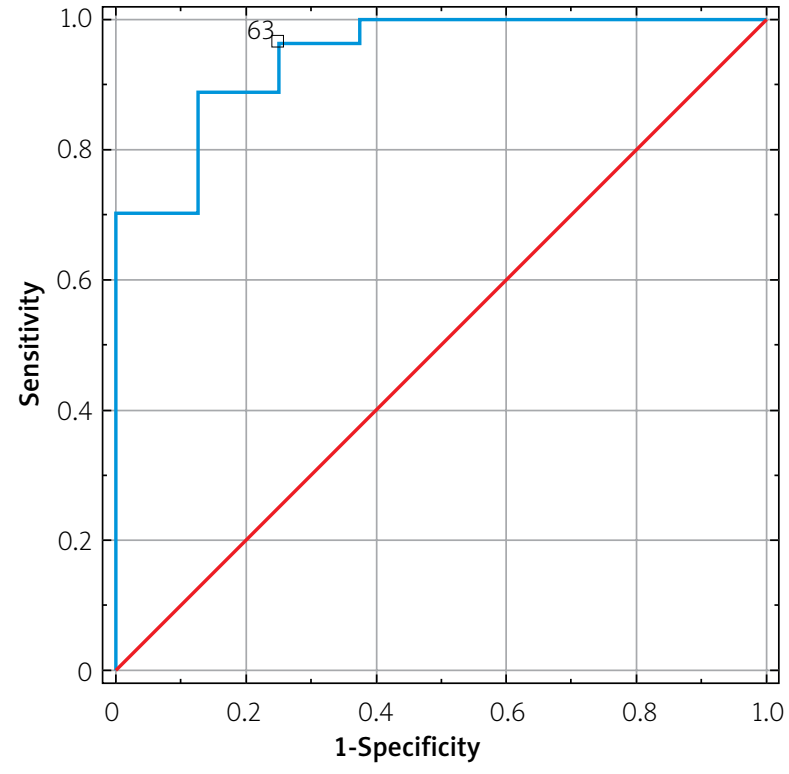

Figure 1. ROC curve for calprotectin

Therefore, it is necessary to monitor the disease activity in order to detect it at its early subclinical stage, as well as taking the cost into account.

In this study, the following testing methods were assessed: clinical evaluation of CDAI disease activity, biomarkers: faecal calprotectin and serum CRP, imaging examinations: ileocolonoscopy, MR enterography.

Diagnostic tests were assessed in terms of their sensitivity and specificity, and in addition they were also compared to each other in order to specify which test is the most effective in quantitating CD activity, taking into consideration the fact that $20.0 \%$ of patients experience early relapses.

In our study, the sensitivity of the CDAI system (with a cut-off value of 150.0 points) was $76.5 \%$, whereas the specificity was a mere $25.0 \%$. The predictive positive value (PPV) was $89.7 \%$, and the predictive negative value (PNV) was $11.1 \%$. The accuracy of this method (ACC), which reflects the correct diagnosis of a patient regardless of the findings, was $71.1 \%$. This can be set in comparison to a study in which CDAI was set against mucosal healing, defined as the lack of ulceration, and where the cut-off value for the disease activity was 150.0 points - PPV amounted to $65.0 \%$ and NPV to $53.0 \%$

In our study, the cut-off value for the process of inflammation was set at the CRP level of $5.0 \mathrm{mg} / \mathrm{dl}$. It was demonstrated that when assessing this parameter in patients with changes limited to the small intestine, the sensitivity and specificity amounted to $66.7 \%$ and $68.8 \%$, respectively. PPV and NPV were at the level of $73.3 \%$ and $67.6 \%$, respectively, whereas the accuracy was estimated at $67.6 \%$. In the case of changes with- in the large intestine, the sensitivity and specificity of this method was estimated at $64.3 \%$ and $88.0 \%$, respectively, with PPV and NPV amounting to $94.7 \%$ and $44.4 \%$, respectively. The accuracy of the method was $70.3 \%$. Without differentiating the range of inflammatory changes, the sensitivity of the method was calculated at $58.8 \%$ with $100.0 \%$ specificity, whereas PPV and NPV stood at $100.0 \%$ and $22.2 \%$, respectively. In this case, the accuracy was estimated at $33.2 \%$.

In a study by Solem et al. [6] it was shown that CRP $<5.0 \mathrm{mg} / \mathrm{dl}$ with a normal endoscopic appearance of the intestinal mucosa was found in $75.0 \%$ of cases, and the elevated CPR level correlated with inflammatory changes. However, another study [25] showed that isolated changes in the ileum corresponded with high CPR values. Mosli et al. [10] conducted a meta-analysis of 19 studies ( $n=2499$ patients with IBD), in which the CRP level was compared with the endoscopic appearance of the mucosa. The sensitivity and specificity of this parameter were calculated at $49 \%$ and $92 \%$, respectively, and it was suggested that CPR $>5.0 \mathrm{mg} / \mathrm{dl}$ may indicate endoscopic inflammatory activity.

Another biomarker, FC, is proportional to the migration of neutrophils to the digestive tract during an ongoing process of inflammation [4, 5, 25, 26].

In our study, the sensitivity and specificity of faecal calprotectin was calculated at $71.9 \%$ and $75.0 \%$, with PPV and NPV of $95.8 \%$ and $25.0 \%$, respectively. The accuracy (ACC) of this method was estimated at $72.2 \%$.

The cut-off value of calprotectin was also determined, depending on the disease activity, which was $43.0 \mu \mathrm{g} / \mathrm{g}$ for the small intestine and $100.0 \mu \mathrm{g} / \mathrm{g}$ for the large intestine $(p<0.0001)$. The area under the curve (ROC AUC) was 0.87 without differentiating the range of changes and 0.944 for the FC value of $100.0 \mu \mathrm{g} / \mathrm{g}$ in the case of the large intestine.

The above values correlated with remission in the endoscopic image, as in the studies by Mosli et al. [10], D'Haens et al. [27, 28], and Roseth et al. [29] showing that the FC level $<50.0 \mu \mathrm{g} / \mathrm{g}$ correlates with a full remission on ileocolonoscopy. The analysis we conducted also showed a difference in the FC value for the activity of the inflammatory process in the small intestine and large intestine, with simultaneous correlation of the endoscopic image with the value of this biomarker.

Other biochemical parameters, such as complete blood count (haemoglobin, platelets) and iron level, did not correlate with the disease activity, and therefore were not included in the analysis.

In imaging examinations, the usefulness of such techniques as ileocolonoscopy or MR enterography was analysed.

The most sensitive and specific method of assessing the activity of inflammation is ileocolonoscopy. Its 
limitation, however, is the scope of the examination because it only reaches the distal segment of the ileum.

In our study, SES-CD was used to assess the inflammation activity during ileocolonoscopy, with cut-off value $<2.0$ points as an indicator of disease inactivity and $>2.0$ points as an indicator of disease activity. The sensitivity of this method was calculated at $93.6 \%$, whereas the specificity was $100.0 \%$. PPV and NPV were $100.0 \%$ and $66.7 \%$, respectively. The accuracy was estimated at $94.6 \%$. Thus, colonoscopy remains the gold standard when diagnosing IBD [30].

When assessing the disease activity using a different imaging technique, i.e. MR enterography, the sensitivity of this diagnostic tool was $51.5 \%$, whereas the specificity was $100.0 \%$. PPV and NPV were $100.0 \%$ and $20.0 \%$, respectively. The accuracy stood at $56.8 \%$.

The sensitivity and specificity of MRE were slightly better for the small intestine: the values were $66.7 \%$ and $100.0 \%$, respectively, with PPV and NPV of $100.0 \%$ and $69.6 \%$. The accuracy was $81.1 \%$. For the large intestine, on the other hand, the sensitivity and specificity were significantly lower: $33.3 \%$ and $100.0 \%$, respectively, with PPV and NPV of $100.0 \%$ and $33.3 \%$. The accuracy of this method for the large intestine was calculated at 50.0\%.

Generally, it is thought that MRE, used as a tool for assessing CD activity, shows an average sensitivity and high specificity within the large intestine [31]. It seems that MRE is a more sensitive diagnostic tool when detecting complications of the disease, such as fistulae or stenoses [27].

All of the diagnostic tools analysed above were also compared to each other, using a non-adjusted coefficient of agreement and Cohen's $\kappa$ coefficient. The comparison showed a strong correlation between an endoscopic examination - colonoscopy - and faecal calprotectin. This once again emphasises that applying faecal calprotectin as a biomarker is an effective method of monitoring the inflammation process and may be used to optimise the therapeutic process.

\section{Conclusions}

By analysing the diagnostic methods used to assess disease activity within the small intestine (the distal segment of the ileum) and the large intestine, it was found that endoscopy is the most accurate diagnostic tool, followed by faecal calprotectin. The least sensitive methods include: MR enterography and CDAI. A statistically significant agreement between endoscopy and faecal calprotectin was demonstrated. The cut-off value of FC (taking into account both the small intestine and the large intestine), in correlation with endoscopic findings indicative of the disease activity, was $43.0 \mu \mathrm{g} / \mathrm{g}$. The cut-off value of FC, in correlation with en- doscopic findings indicative of the disease activity, was $100.0 \mu \mathrm{g} / \mathrm{g}$ for the large intestine. CRP shows statistical significance with CDAI, and it correlated with the endoscopic appearance of the large intestine, MRE of the small intestine, and the faecal calprotectin level. By assessing the inflammation activity for the small and large intestine separately, it was found that MRE is a slightly better diagnostic tool in the case of the small intestine, whereas ileocolonoscopy is a preferred method for examining the large intestine.

\section{Conflict of interest}

The authors declare no conflict of interest.

\section{References}

1. Stange EF, Travis SPL, Vermeire S, et al. European evidence based consensus on the diagnosis and management of Crohn's disease: definitions and diagnosis ECCO Consensus. Gut 2006; 55 (Suppl I): 1-15.

2. Sands BE. Biomarkers on inflammation in inflammatory bowel Disease. Gastroenterology 2015; 149: 1275-85.

3. Wu F, Guo NJ, Tian H, et al. Peripheral blood micro RNAs distinguish active ulcerative colitis and Crohn's disease. Inflamm Bowel Dis 2011; 17: 241-50.

4. Vermeire S, Van Assche G, Rutgeerts P. Laboratory markers in IBD: useful, magic, or unnecessary toys? Gut 2006; 55: 426-31.

5. Tilett WS, Francis T. Serological reactions in pneumonia with a non-protein somatic fraction of pneumococcus. J Exp Med 1930; 52: 561-71.

6. Solem CA, Loftus EV, Tremaine WJ, et al. Correlation of C-reactive protein with clinical, endoscopic, histologic, and radiographic activity in inflammatory bowel disease. Inflamm Bowel Dis 2005; 11: 707-12.

7. Karoui S, Ouerdiane S, Serghiani M, et al. Correlation between levels of C-reactive protein and clinical activity in Crohn's disease. Dig Liver Dis 2007; 39: 1006-10.

8. Tilakaratne S, Lemberg DA, Leach ST, Day AS. C-reactive protein and disease activity in children with Crohn's disease. Dig Dis Sci 2010; 55: 131-6.

9. Jones J, Loftus EV, Panaccione R, et al. Relationships between disease activity and serum and fecal biomarkers in patients with Crohn's disease. Clin Gastroenterol Hepatol 2008; 6 : 1218-24.

10. Mosli MH, Zou G, Garg SK, et al. C-reactive protein, fecal calprotectin, and stool lactoferrin for detection of endoscopic activity in syptomatic inflammatory bowel disease patients: a systematic review and meta-analysis. Am J Gastronterol 2015; 110: 802-19.

11. Smith LA, Gaya DR. Utility of faecal calprotein analysis in adult inflammatory bowel disease. World J Gastroenterol 2012; 18 : 6782-9.

12. Fagerhol MK, Dale I, Andersson T. A radioimmunoassay for a granulocyte protein as a marker in studies on the turnover of such cells. Bull Eur Physiopathol Respir 1980; 16 Suppl: 273-82.

13. Konikoff MR, Denson LA. Role of faecal calprotectin as a biomarker of intestinal inflammation in inflammatory bowel disease. Inflamm Bowel Dis 2006; 12: 524-34. 
14. Whitead SJ, French J, Brookes MJ, et al. Between-assay variability of faecal calprotectin enzyme- linked immunosorbent assay kits. Ann Clin Biochem 2013; 50: 53-61.

15. Moniuszko A, Głuszek S, Rydzewska G. Rapid fecal calprotectin test for prediction of mucosal inflammation in ulcerative colitis and Crohn disease: a prospective cohort study. Pol Arch Intern Med 2017; 127: 312-8.

16. Yacoub JH, Obara P, Oto A. Evolving role of MEI in Crohn's disease. J Magn Reson Imaging 2013; 37: 1277-89.

17. Fiorino G, Bonifacio C, Peyrin-Biroulet L, et al. Prospective comparison of computed tomography esterography and magnetic resonance enterography for assessment of disease activity and complications in ileocolonic Crohn's disease. Inflamm Bowel Dis 2011; 17: 1073-80

18. Van Assche G, Dignass A, Panes J, et al. The second European evidence-based consensus on the diagnosis and management of Crohn's disease: definitions and diagnosis. J Crohns Colitis 2010; 4: 7-27.

19. Lee SS, Kim AY, Yang SK, et al. Crohn Disease of the small bowel: comparison of CT enterography, MR enterography, and small-bowel follow - trough as diagnostic techniques 1 . Radiology 2009; 251: 751-61.

20. Sinha R, Verma R, Verma S, Rajesh A. MR enterography of Crohn disease: part 1, rational, technique, and pitfalls. AJR Am J Roentgenol 2011; 197: 76-9.

21. Siddiki H, Fidler J. MR imaging of the small bowel in Crohn's disease. Eur J Radiol 2009; 69: 409-17.

22. Ordas I, Rimola J, Rodriguez S, et al. Accuracy of magnetic resonance enterography in assessing response to therapy and mucosal healing in patients with Crohn's disease. Gastroenterology 2014; 146: 374-82.

23. Sipponen T, Nuutinen H, Turunen U, Farkkila M. Endoscopic evaluation of Crohn's disease activity: comparison of the CDEIS and the SES-CD. Inflamm Bowel Dis 2010; 16: 2131-6.

24. Orzędała-Koszel U, Bachanek T, Karczmarek-Borowska B. Białko C-reaktywne jako czynnik diagnostyczny w stanach zapalnych jamy ustnej i chorobach nowotworowych. Dent Med Probl 2005; 42: 131-6.

25. Hanriksen $M$, Jahnsen J, Lygren I, et al. C-reactive protein a predictive factor and marker of inflammation in inflammatory bowel disease. Results from a prospective population-based study. Gut 2008; 57: 1518-23.

26. Poulsen NA, Andersen V, Moller JC, et al. Comparative analysis of inflamed and non- inflamed colon biopsies reveales strong proteomic inflammation profile in patients with ulcerative colitis. BMC Gastroenterol 2012; 12: 76.

27. D'Haens G, Ferrante M, Vermeire S, et al. Faecal calprotectin is a surrogate marker for endoscopic lesions in inflammatory bowel disease. Inflamm Bowel Dis 2012; 18: 2218-24.

28. Felvey JD, Hoskin T, Meijer B, et al. Disease activity assessment in IBD: clinical indices and biomarkers fail to predict endoscopic remission. Inflamm Bowel Dis 2015; 21: 824-31.

29. Roseth AG, Aadland E, Grzyb K. Normalization of faecal calprotein: a predictor of mucosal healing in patients with inflammatory bowel disease. Scand J Gastroenterol 2004; 39: 1017-20.

30. Delefortrie Q, Schatt P, Grimmelprez A, et al. Comparison of the Liasion Calprotectin kit with a well established point of car test (Quantum Blue - Buhlmann- Alere) in terms of analytica performances and ability to detect relapses amongst a Crohn population in follow-up. Clin Biochem 2016; 49: 268-73.

31. Aryan A, Azizi Z, Teimouri A, et al. The diagnostic role of magnetic resonance enterography as a complementary test in activity Crohn's disease. Middle East J Dig Dis 2016; 8: 93-101.

Received: 3.10.2019

Accepted: 16.02 .2020 